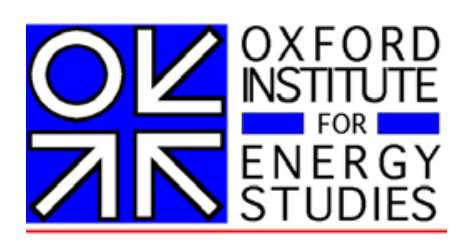

\title{
The Dynamics of Crude Oil Price Differentials
}

\author{
Bassam Fattouh
}

Centre for Financial and Management Studies, SOAS

and

Oxford Institute for Energy Studies

January 2008 
The contents of this paper are the sole responsibility of the author. They do not necessarily represent the views of the Oxford Institute for Energy Studies or any of its Members.

Copyright (C) 2008

\section{Oxford Institute for Energy Studies}

(Registered Charity, No. 286084)

This publication may be reproduced in part for educational or non-profit purposes without special permission from the copyright holder, provided acknowledgment of the source is made. No use of this publication may be made for resale or for any other commercial purpose whatsoever without prior permission in writing from the Oxford Institute for Energy Studies.

\section{ISBN}

978-1-901795-70-7 


\section{Contents}

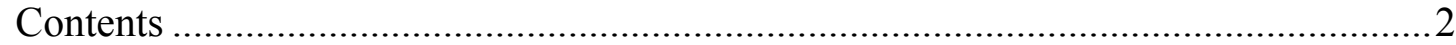

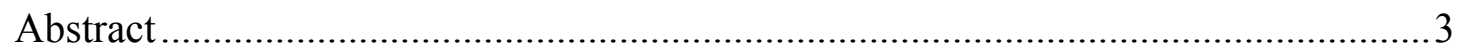

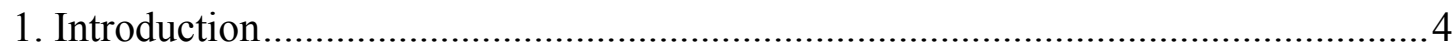

2. Some Features of Crude Oil Price Differentials .................................................... 7

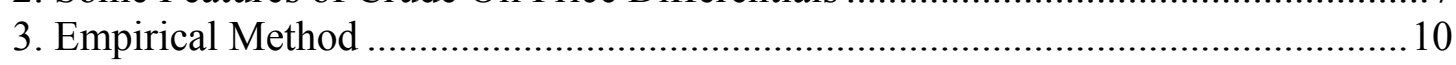

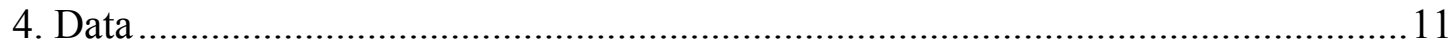

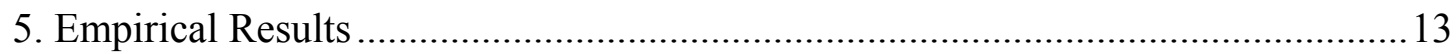

5.1 Dynamics of Price Differential between Crude Oils of Different Quality.........13

5.2 Price Differentials between Crude Oils of Similar Quality .................................15

5.3 Price Differentials between Crude Oils one of which is Linked to an Active

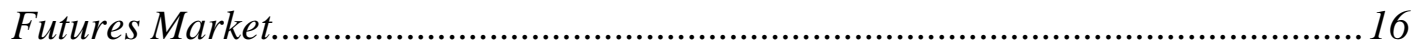

5.4 Price Differentials between Crude Oils both with Tradable Paper Contract ... 17

5.5 Discussion of the Empirical Results ...............................................................17

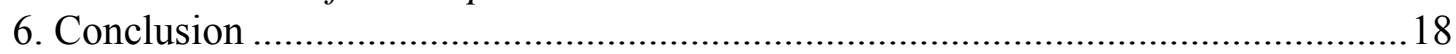

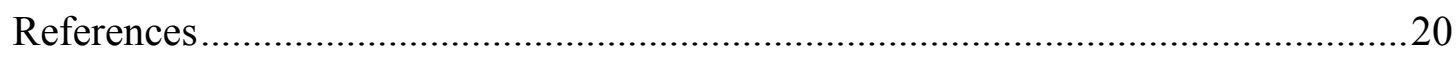

\section{Tables}

Table 1: Pairs of Crude Oil Price Differentials Analysed..........................................22

Table 2: Sahara-Maya Price Differential ............................................................2 23

Table 3: Estimation of Threshold Autoregressive Model (Sahara-Maya) ..................24

Table 4: Bonny-Maya Price Differential...............................................................25

Table 5: Estimation of Threshold Autoregressive Model (Bonny-Maya) ..................26

Table 6: Sahara-Bonny Price Differential ...............................................................2

Table 7: Estimation of Threshold Autoregressive Model (Sahara-Bonny)................28

Table 8: Maya-Lloyd Blend Price Differential .....................................................29

Table 9: Estimation of Threshold Autoregressive Model (Maya-Lloyd Blend) ..........30

Table 10: WTI-Maya Price Differential....................................................................... 31

Table 11: Estimation of Threshold Autoregressive Model (WTI-Maya) ......................32

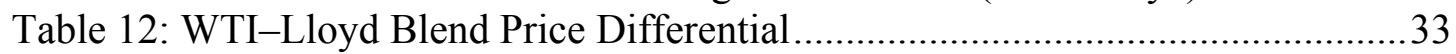

Table 13: Estimation of Threshold Autoregressive Model (WTI-Lloyd Blend) .........34

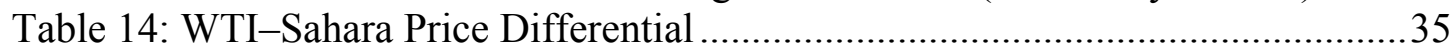

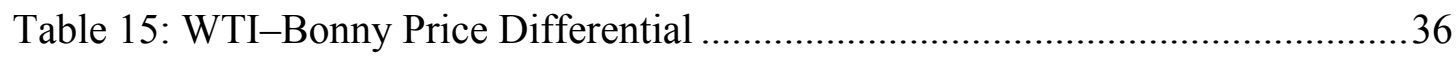

Table 16: Estimation of Threshold Autoregressive Model (WTI-Bonny) ...................36

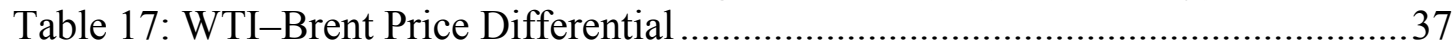

Table 18: WTI-Dubai Price Differential........................................ 37

Table 19: Estimation of Threshold Autoregressive Model (Dubai-Maya) ..................38

\section{Figures}

Figure 1: Behaviour of Crude Oil Price Differential.............................................. 39

Figure 2: Identification of Threshold Regime for Sahara-Maya............................. 40

Figure 3: Identification of Threshold Regime for Sahara-Bonny ............................ 41 


\begin{abstract}
We model crude oil price differentials as a two-regime threshold autoregressive (TAR) process using Caner and Hansen's (2001) method. While standard unit root tests, such as the Augmented Dickey-Fuller (ADF), are inconclusive in some instances on whether oil price differentials follow a stationary process, the null hypothesis of unit root can be strongly rejected based on the threshold unit root test, even for crude oils with very different qualities. Our results also indicate that the adjustment process is different depending on whether one considers the differentials between crude oils of similar quality or between oils of different quality and whether a crude oil is part of a complex that involves a highly liquid tradable futures contract. These findings suggest that the different oil markets are linked and thus, at the very general level, the oil market is 'one great pool'. However, differences in the dynamics of adjustment suggest that within this one great oil pool, oil markets are not integrated in every time period and, although the presence of an active futures market has helped make some distant markets more unified, arbitrage across the different markets is not costless or risk-free.
\end{abstract}




\section{Introduction}

Despite the wide variety of internationally traded crude oils with different qualities and characteristics (the 2006 International Crude Oil Market Handbook describes more than 160 traded crude oil streams), many observers consider the world oil market as 'one great pool' (Adelman, 1984). Others argues that oil markets are 'globalized' in the sense that supply and demand shocks that affect prices in one region are transferred into other regional markets (Weiner, 1991). One implication of the globalization thesis is that prices of similar crudes in different markets should move closely together such that their price differential is more or less constant. This is in contrast to oil markets being 'regionalized' in which oil prices of similar qualities move independently to each other in response to shocks. Whether the oil market is one great pool or is regionalized has important implications in terms of energy policy and market efficiency. For instance, Weiner (1991) argues that the effectiveness of government policies, such as releasing crude oil from the Special Petroleum Reserve (SPR), depends to a large extent on whether the impact of such policy action extends to other regions or remains confined to the US market. In terms of efficiency, Gülen (1999) argues that regionalization gives rise to arbitrage opportunities across local oil markets and may render the market inefficient if arbitrage fails to push prices of similar crude oils in different markets in line with each other.

The empirical evidence on 'globalized' oil markets is mixed. Using simple correlation analysis and a switching regression system, Weiner (1991) finds support for a high degree of 'regionalization' across oil markets. More recent empirical studies that use cointegration methods find that oil prices in different markets move closely together even in short horizons providing support for the 'globalization' hypothesis (Gülen, 1997; 1999). Using an empirical method that generates estimates of arbitrage costs between regions (called the arbitrage cost approach), Kleit (2001) finds that oil markets have become more unified, as evidenced by the reduction in transaction costs over time. Interestingly, though, his results indicate the existence of important transaction (arbitrage) costs between oil markets. Milonas and Henker (2001) examine the price differential between Brent and West Texas Intermediate (WTI) and conclude that the Brent and WTI markets are not fully integrated.

In this paper, we present new evidence in this debate by analysing the dynamic behaviour of crude oil price differentials. Although prices of various crude oils may evolve independently for a period of time, their movements are unlikely to deviate very widely such that their price differential would increase or decrease without bounds and hence we expect the differential to follow a stationary process. After all, crude oil prices are linked through the cost-of-carry relationship and any deviation from this relationship would be restored through arbitrage. 
These dynamics are most likely to be present for crude oils of similar quality and with liquid futures market such as the Brent-West Texas Intermediate (WTI) complex. Specifically, Brent and WTI are linked through the following relationship (Kinnear, 2001; Alizadeh and Nomikos, 2004):

$$
P_{B R, t}+C_{B R}+D=P_{W T I, t}
$$

where $P_{B R}$ and $P_{W T I}$ are the prices of dated Brent and WTI at time $t, \mathrm{C}_{B R}$ represents the carrying costs which are necessary to transport the physical Brent and include insurance, losses, custom duty costs, and pipeline tariff, and $D$ is the quality discount (usually 0.30 cents). If the WTI-Brent price differential, adjusted for carrying costs, is greater than zero, this would open the trans-Atlantic arbitrage window, i.e. refiners in the USA would increase their imports of Brent and those crude oils priced off Brent. The trans-Atlantic window would remain open until the price relationship in (1) is attained. The highly liquid futures market in both Brent and WTI has increased the ability of market participants to trade the WTI-Brent arbitrage speedily (Kinnear, 2001).

In the absence of transaction (arbitrage) costs, the deviation of the price differential (adjusted for carrying costs) from zero would always trigger arbitrage. However, as Balke and Fomby (1997) observe, the existence of adjustment costs or transaction costs implies that movements towards some long-run equilibrium value do not need to occur instantaneously and in a linear fashion. This type of discrete adjustment process has been used to describe many economic phenomena, such as the behaviour of inventories, interest rates, and investment.

We extend this type of discrete adjustment to oil price differentials, especially for those types of crude oil with different qualities and/or crude oils that are not linked to an active futures market. Specifically, crude oil price differentials are modelled as a two-regime threshold autoregressive (TAR) ${ }^{1}$ process using Caner and Hansen's (2001) method. The threshold approach decomposes the model into different regimes and thus allows the oil price differential to follow different dynamics, depending on whether the differential is above or below a certain threshold. These different dynamics could be explained by the existence of transaction costs. Although persistent deviations from the equilibrium relationship give rise to arbitrage opportunities, transaction costs may be high enough such that it would not make it profitable for traders and refineries to exploit available arbitrage opportunities that would

\footnotetext{
${ }^{1}$ In the absence of transaction costs, any deviation, whether negative or positive, of the price differential (adjusted for carrying costs) from zero would trigger arbitrage. This would suggest that we should include two thresholds and three regimes. However, a model with two regimes is more suitable for our purpose since, as we shall see later, in many cases the differential takes either a positive or a negative value. The inclusion of an additional threshold would have been spurious in this context.
} 
restore the equilibrium price relationship unless the oil price differential crosses a certain threshold. These transaction costs may arise due to the fact that as 'commodities' trading times overlap only for a few hours, simultaneous position taking is limited. Also, another obstacle for integration is that the delivery instruments differ. Furthermore, because the delivery of the underlying commodity is costly, riskless arbitrage is not possible' (Milonas and Henker, 2001, p. 36). These types of obstacles are likely to be more present in arbitraging crude oil of different quality and not linked to an active futures market.

In this paper, we study the dynamic behaviour of price differentials between various types of crude oil. Firstly, we examine the behaviour of price differentials between crude oils of similar quality (light/light or heavy/heavy). For this group, the price differential is expected to follow a stationary process, although it is possible to find threshold effects such that errorcorrection dynamics become stronger if the differential exceeds a certain threshold.

Secondly, we analyse the behaviour of price differentials of crude oils with different qualities (light/heavy). Since these types of crude oils do not directly compete with each other and given that refineries are configured to deal with specific types of crude oil, their prices are likely to evolve independently and hence their price differential may not follow a stationary process for the entire period under study. However, we argue that these crude oils cannot diverge from each other in such a way that their price differential would increase or decrease without bounds. We expect that once the oil price differential crosses a certain threshold, arbitrage would become profitable, pushing the differential back to below the threshold. For instance, it could be argued that refineries would be willing to take delivery and process heavy crude only if the discount to light crudes is large enough to compensate them for running their refineries on less suitable crudes. Furthermore, if heavy oil is trading at a large discount to light crude oil, some oil producers may decide to cut supplies of heavy crude, raising its price and narrowing the price differential. Thus, for pairs of price differentials between different quality crudes, we expect to find evidence of threshold stationarity such that below the threshold, arbitrage 'switches off', allowing the oil price differential to behave as a random walk. Adjustment dynamics would only be triggered if the oil price differential crosses that threshold.

Finally, to explore whether a highly liquid futures market reduces transaction costs by facilitating arbitrage, we examine the price differentials between various types of crude oils and WTI, Brent, and Dubai. WTI and Brent have the most liquid contracts on a physical commodity while Dubai is the only non-light crude that has a contract tradable over the counter. We expect the dynamics of price differential to differ depending on whether a crude oil is part of a complex that involves a highly liquid tradable futures contract. 
This paper reveals the following interesting findings. Firstly, while standard unit root tests, such as the Augmented Dickey-Fuller (ADF), are inconclusive in some instances as to whether oil price differentials follow a stationary process, we can strongly reject the null hypothesis of unit root based on the threshold unit root test which has better power than standard unit root tests when the underlying process is non-linear (Caner and Hansen, 2001). These findings do not apply only to crude oils with similar qualities, but more importantly to crude oils with different qualities. This evidence suggests that oil price differentials cannot deviate without bounds, providing support for the 'globalization' hypothesis.

Secondly, our results indicate that the adjustment process is different depending on whether one considers the differentials between crude oils of similar quality or between oils of different quality. For the latter, we find strong evidence of threshold effects in the adjustment process. Specifically, below an estimated threshold, there is no evidence of stationarity, suggesting that these oil price differentials follow a random walk in that regime. However, once the price differential crosses the estimated threshold, there is evidence of mean reversion. These threshold effects indicate the existence of transaction costs, which is consistent with Kleit's analysis (2001). It is also consistent with the conclusion of Milonas and Henker (2001) in the WTI-Brent context, where they argue that these two markets are 'not fully integrated and this cannot be overcome with the operation of riskless arbitrage'.

Finally, our findings suggest that whether one or both of the crude oils is linked to a highly liquid futures market affect the dynamics of some crude oil price differentials by eliminating threshold effects. This applies mainly to crude oils of similar quality but in some instances to crude oils of different quality. These dynamics may reflect the fact that a crude oil with a highly tradable contract reduces transaction costs and facilitates arbitrage and hence error correction dynamics would always be present and would not be triggered by threshold effects.

This paper is divided into four further sections. In Section 2, we outline the various features of crude oil price differentials. In Section 3, we describe the empirical method used. Section 4 describes the data while Section 5 reports and discusses the empirical results. The last section provides a conclusion.

\section{Some Features of Crude Oil Price Differentials}

Crude oil is of little use before refining and is traded for its final petroleum products that consumers demand. The intrinsic properties of the crude oils determine the mix of the final petroleum products. The two most important qualities of crude oil are viscosity (thickness or 
density) and sulphur content. ${ }^{2}$ Crude oils with lower density (referred to as light crude) usually yield a higher proportion of the more valuable final petroleum products, such as gasoline and other light petroleum products, by a simple refining process known as distillation. Light crude oils are contrasted with heavy crude oils that have a low share of light hydrocarbons and require much more severe refining processes than distillation, such as coking and cracking, to produce similar proportions of the more valuable petroleum products. ${ }^{3}$ Sulphur, a naturally occurring element in crude oil is an undesirable property and refiners have to make heavy investments in order to remove it from crude oils. Crude oils with high sulphur content are referred to as sour crudes while those with low content of sulphur are referred to as sweet crudes. Since the type of crude oil has a bearing on refining yields, different types of crude oil fetch different prices. Crude oils that yield a higher proportion of the more valuable final petroleum products and require a simple refining process (the light/sweet crude variety) usually command a premium over those that yield a lower fraction of the more valuable petroleum products and require a more severe refining process (the heavy/sour crude variety).

However, differences in the quality of crude oils are not the only determinant of oil price differentials and hence differentials are not constant over time. Variation in oil price differentials can result from non-parallel movement of either the underlying crude oils or both. These non-parallel movements are possible because each type of crude oil may be influenced by local conditions. Milonas and Henker (2001) argue that demand for oil has a seasonal component which is unlikely to affect two types of crude oil in the same way. In addition, squeezes in some markets can cause the price of lower quality crude to rise sharply in relation to higher quality crude, causing the differential to switch from positive to negative values. The variation in oil price differentials can also be driven by changes in the relative demand for light and heavy final petroleum products, which can feed into the crude market and alter the price differentials between crude oils.

Figure 1 plots the price differential between WTI, Brent, and Dubai. These varieties represent the main crude oil benchmarks of the current international oil pricing system. ${ }^{4}$ Because there are many varieties of crude oil, buyers and sellers usually price the crude at a discount or a premium to particular benchmarks. Nearly all oil traded outside the USA and the Far East is

\footnotetext{
${ }^{2}$ Density is usually measured by API degrees $\left({ }^{\circ}\right)$. Crude oil with high API has a low density and flows freely at room temperature.

${ }^{3}$ Not all refiners, however, have the technical capacity to undertake such a complex refining operation. The least complex refineries that use heavy crude will obtain a lower yield of the more valuable light refined products and higher yield of the less valuable heavy refined products, reducing their profit margins.

${ }^{4}$ For details see Horsnell and Mabro (1993) and Fattouh (2006).
} 
priced using Brent as a benchmark while oil traded to the USA is priced off WTI. Dubai is the main benchmark for Middle Eastern exports to Asia. WTI is a very high quality crude with API of $39.6^{\circ}$ and contains only about 0.24 per cent of sulphur. Given these qualities, WTI is considered as light/sweet crude. Brent blend is a combination of crude oil from different oil fields located in the North Sea. Its API gravity is $38.3^{\circ}$ while it contains about 0.37 per cent of sulphur, making it light/sweet crude oil, but slightly less so than WTI. Dubai's API gravity is $32^{\circ}$ and contains a high sulphur content of around 2 per cent and thus is considered to be of sour/heavy variety.

Three important features emerge from Figure 1. As expected, sweet/light crude varieties (WTI and Brent) usually trade at a premium to sour/heavy crude varieties (Dubai). However, there are few exceptions to this rule where the higher quality crude was trading at a discount from the lower quality crude. For instance, during September 2000 due to a successful squeeze of the Brent market, the price of Brent rose almost $\$ 3$ above that of WTI although WTI is of better quality than Brent and usually trades at a premium. In 2007, and as a result of a large build-up of stockpiles driven by purely infrastructure logistics, the WTI price decoupled not only from the rest of the world, but also from other US regions, particularly from the US Gulf (Fattouh, 2007). This was reflected in the large differential between the prices of the two international benchmarks when the discount of WTI to Brent reached more than $\$ 6.50$ in April 2007.

The second feature is that the discount of heavy crude oil to light crude oil could in some occasions reach very high levels. Many observers have highlighted the rise in demand for light products and inflexibility of refineries as the main factors for the recent widening of differentials. The refining industry in the past decade or so has lost much of the needed flexibility given the changes in the structure of demand for its products, the mandated modification of product specifications and other environmental restrictions, and the changing mix of its crude slate due to higher incremental volumes of sour and heavier crudes. The increase in demand for gasoline in recent years and constraints on conversion capacity resulted in an increase in demand for crude oils that yield a large proportion of gasoline. ${ }^{5}$ This widened the differential between light/sweet and heavy/sour crude oils considerably. For exporters of low quality crude oils, this has important implications on government revenues

\footnotetext{
${ }^{5}$ For most of the past decade returns on investment in refining were quite low, which meant that many refiners were unable to justify significant investment in de-sulphurization. As regulation became law, many refiners chose the easy option of purchasing lower sulphur crude oil feedstocks rather than the option of investing in sulphur-removal facilities. This has pushed refiners to bid up prices of light/sweet crude oils in order to reach the new environmental standards.
} 
(Bacon and Tordo, 2005). It also can influence investment decisions by sending strong signals about the type of refining capacity that the market needs.

The third and most important feature for our analysis is that there has been large variation in oil price differentials over time, especially in the last two years of the sample. This recent behaviour of oil price differentials has raised some doubts about whether oil markets have become more integrated in recent years, especially between crude oils with different qualities.

\section{Empirical Method}

We model the oil price differential dynamics as a two-regime TAR process. ${ }^{6}$ The TAR model can be written as:

$$
\Delta y_{t}=\theta_{1}^{\prime} X_{t-1} I_{\left\{Z_{t-1}<\lambda\right\}}+\theta_{2}^{\prime} x_{t-1} I_{\left\{Z_{t-1} \geq \lambda\right\}}+u_{t}
$$

where $t=1, \ldots, T ; x_{t-1}=$ (intpt, $\left.y_{t-1}, \Delta y_{t-1}, \ldots, \Delta y_{t-k}\right)^{\prime}$ where $y$ is oil price differential; I(.) is the indicator function; $Z_{t-1}$ is the threshold variable defined as $Z_{t-1}=y_{t-m}$ for some $m \geq 1$ where $m$ is the delay $\operatorname{order}^{7}$; and $u_{t}$ is an iid mean-zero sequence of error terms. The deterministic component intpt stands for an intercept; $\Delta y_{t-j}=y_{t-j}-y_{t-j-1}$ is the first order difference at lag $j$. The threshold $\lambda$ is unknown and takes values in the interval $\lambda \in \Lambda=\left[\lambda_{1}, \lambda_{2}\right]$, where $\lambda_{1}$ and $\lambda_{2}$ are chosen so that $\operatorname{Prob}\left(Z_{t} \leq \lambda_{1}\right)=\pi_{1}>0$ and $\operatorname{Prob}\left(Z_{t} \leq \lambda_{2}\right)=\pi_{2}<1 .{ }^{8}$ It is convenient to consider the vectors $\theta_{1}=\left(\rho_{1} \beta_{1} \alpha_{1}\right)^{\prime}$ and $\theta_{2}=\left(\rho_{2} \beta_{2} \alpha_{2}\right)^{\prime}$, where $\rho_{1}$ and $\rho_{2}$ are the slopes on the lagged levels, $\beta_{1}$ and $\beta_{2}$ are the slopes on the deterministic component, and $\alpha_{1}$ and $\alpha_{2}$ are the slopes on the lagged differences in the two regimes.

When estimating the TAR model, for each $\lambda \in \Lambda$, we estimate $\theta_{1}$ and $\theta_{2}$ by Least Squares (LS). The LS point estimate of the threshold $\hat{\lambda}$ is found by minimizing the residual sum of squares. The corresponding vectors $\hat{\theta}_{1}$ and $\hat{\theta}_{2}$ are then found by plugging in the point estimate such that the estimated model can be written as:

\footnotetext{
${ }^{6}$ For details of the empirical method, see Caner and Hansen (2001). The discussion in this section is based on their paper.

${ }^{7}$ The delay parameter represents the time lag that it takes the market to respond to deviation from equilibrium.

${ }^{8}$ The authors suggest that, setting the bounds of the trimming region to $\pi_{1}=0.10$ and $\pi_{2}=0.90$, provides a reasonable trade-off between the power and size properties of the test for threshold effects (see Caner and Hansen, 2001, for details). However, as the authors observe, since this particular choice is somewhat arbitrary, it would be sensible in practical applications to explore the robustness of the results to this choice. Our results are robust in this sense.
} 


$$
\Delta y_{t}=\hat{\theta}_{1}^{\prime} x_{t-1} I_{\left\{z_{t-1}<\hat{\lambda}\right\}}+\hat{\theta}_{2}^{\prime} x_{t-1} I_{\left\{z_{t-1} \geq \hat{\lambda}\right\}}+\hat{u}_{t}
$$

To test the null hypothesis of linearity, that is $H_{0}: \theta_{1}=\theta_{2}$, against the alternative of threshold effects, Caner and Hansen suggest the use of the sup-Wald statistic, $W_{T}$. The latter is not identified under the null, and its asymptotic distribution under the assumption of stationary data was investigated by Davies (1987) and Hansen (1996). Caner and Hansen (2001) find that under the restriction of a unit root process, the asymptotic distribution of $W_{T}$ depends on the data structure, which implies that critical values cannot be tabulated, and, therefore, the authors suggest two bootstrap methods to approximate the asymptotic distribution of $W_{T}$, one of which is appropriate for the stationary case while the other is appropriate for the unit root case. If the true order of integration is unknown, then Caner and Hansen (2001) suggest to calculate the bootstrap critical values and $p$-values both ways, and base inference on the more conservative (larger) $p$-value.

As for the unit root tests, the following statistics are employed: the two-sided Wald test statistic, $R_{2 T}$, for the null of unit root, $H_{0}: \rho_{1}=\rho_{2}=0$, against the alternative $H_{1}: \rho_{1} \neq 0$ or $\rho_{2}$ $\neq 0$ and the one-sided Wald test statistic, $R_{1 T}$, for the null of unit root, $H_{0}: \rho_{1}=\rho_{2}=0$, against the alternative $H_{1}: \rho_{1}<0$ or $\rho_{2}<0$. Although both statistics have the power to test against the null of unit root, they cannot discriminate between the stationarity case and the partial unit root case where the partial unit root case refers to a situation in which the process is stationary in one regime but has a unit root in the other.

To test for the interesting case of a partial unit root, Caner and Hansen suggest the use of individual $t$ statistics, $t_{1}$ and $t_{2} ; t_{1}$ tests for the null of unit root, $H_{0}: \rho_{1}=\rho_{2}=0$, against the alternative of stationarity only in regime 1 , that is, $H_{1}: \rho_{1}<0$ and $\rho_{2}=0$, and the one-sided Wald test statistic, $t_{2}$, tests for the null of unit root, $H_{0}: \rho_{1}=\rho_{2}=0$, against the alternative of stationarity only in regime 2 , that is, $H_{1}: \rho_{1}=0$ and $\rho_{2}<0$. If there are no threshold effects (unidentified case), the asymptotic distribution of each of the four statistics is found to be dependent on the data structure. However, asymptotic bounds, free of nuisance parameters other than the trimming range, are found. Consequently, critical values can be tabulated and $p$-values can be computed (Table 3 in Caner and Hansen, 2001). As for the asymptotic distribution of each of the four statistics in the presence of threshold effects (identified case), the authors found that the Dickey-Fuller tabulated critical values provide a conservative bound for the $t_{1}$ and $t_{2}$ tests.

\section{Data}

Given the large variety of crude oils traded in the international market, it is important to limit our analysis to few crude streams. In this paper, we focus our analysis on the following seven 
types of crude oils imported into the USA: Nigerian Bonny Light $\left(37^{\circ}\right)$, Algerian Saharan Blend $\left(44^{\circ}\right)$, Mexican Maya $\left(22^{\circ}\right)$, Canadian Lloyd Blend $\left(22^{\circ}\right)$, West Texas Intermediate $\left(40^{\circ}\right)$, Brent $\left(38^{\circ}\right)$, and Dubai's Fateh $\left(32^{\circ}\right)$. This choice of crude oils allows us to examine the time series properties of the following cases:

- The price differential between crude oils with different quality such as Sahara-Maya or Bonny-Maya.

- The price differential between crude oils with similar characteristics such as SaharaBonny (light/light) and Maya-Lloyd Blend (heavy/heavy).

Focusing on these differentials allows us to test whether the adjustment process towards the long equilibrium between crude oils of same quality differs from the adjustment process between crude oils of different quality. Furthermore, it allows us to test whether prices of crude oils of very different quality move together such that their price differential is stationary. Evidence of stationarity would provide stronger support for the globalization hypothesis as it implies that light and heavy crude oil markets are linked together through arbitrage. Existing empirical evidence on the behaviour of prices of crude oil of different quality is very thin. The only exception is Gülen's (1999) study where he finds that Saudi Arabia heavy crude moves closely with prices of lighter crude oils in the sub-periods when oil prices have been rising.

The above pairs of crude oil price differentials are not linked to a complex that includes a futures contract. In order to explore the impact of futures market activity, we also examine the adjustment process between crude oils that do not have a paper contract (Bonny, Maya, Sahara, Lloyd Blend) on the one hand and other crude streams that have paper contracts which are actively traded on the futures market or over the counter (WTI, Brent, and to lesser extent Dubai). Thus, we also consider the following cases:

- The price differential between pairs of crude oils of similar quality but one of which has a paper contract that is highly traded on the futures market, such as Sahara-WTI and Bonny-WTI (light/light).

- The price differential between pairs of crude oils of different quality but one of which has a paper contract, such as WTI-Maya and WTI-Lloyd Blend (light/heavy).

- The price differential between WTI and Brent, which are of similar quality and are both actively traded on the futures market.

- The price differential between pairs of crude oils of different quality but both of which have paper contracts actively traded, namely WTI-Dubai. 
Table 1 summarizes the 10 pairs of crude oils analysed in this paper. We use weekly data for the period 1/1/1997 to 26/10/2007 which yield a sample size of 563 observations. ${ }^{9}$ All the series were obtained from Energy Information Administration (EIA) and are expressed in US dollars per barrel. The price differentials are computed as the simple difference between the prices of the above pairs of crude oils.

\section{Empirical Results}

The first step in our empirical analysis is to establish whether a price differential is stationary based on the various unit root tests, namely the Augmented Dickey-Fuller (ADF), PhilipPerron (1988), and ADF-GLS test developed by $\mathrm{Ng}$ and Perron (2001). If evidence of stationarity based on these unit root tests is found, we do not carry the threshold unit root test (discussed in step 3 below). On the other hand, if we find evidence of a unit root at this initial stage, we carry the threshold stationarity test. The power of unit root tests such as ADF is considerably reduced in the presence of non-linearities and as such standard unit root tests that do not take into account the possibility of threshold effect and asymmetric adjustment in oil price differential may reach erroneous conclusions regarding the dynamics of oil price differentials. In the second step, we test for the linearity of our model using the sup-Wald statistic, $W_{T}$. The optimal number of lags is selected using the AIC criterion while the delay parameter is selected such that the value of sup-Wald statistic, $W_{T}$, is maximized. This is equivalent to choosing $m$ that minimizes the residual variance since $W_{T}$ is a monotonic function of the residual variance. In the third step, we test whether the oil price differential follows a stationary or a random walk process using the two-sided Wald test statistic, $R_{2 T}$, and the one-sided Wald test statistic, $R_{1 T}$. In the fourth step, we report the OLS estimates of the TAR model. We also test for the equality of the coefficients on lagged level and the coefficients on lagged differences across the two regimes using a joint Wald test. This would allow us to test which variables are driving the non-linear dynamics in our model.

\subsection{Dynamics of Price Differential between Crude Oils of Different Quality}

Table 2 reports the results for the Sahara-Maya price differential. As can be seen from the first part of the table, the various tests indicate that the null of unit root cannot be rejected at the conventional levels. In part 2 of the Table 2, we report the sup-Wald statistic and the corresponding bootstrap $p$-values both for the stationary and unit root cases. As can be seen from this table, the null hypothesis of linearity against the alternative of threshold effects can be rejected at the 1 per cent level based on both $p$-values. We next test whether the oil price differential follows a stationary or a random walk process using the two-sided Wald test

\footnotetext{
${ }^{9}$ Data on the Canadian Lloyd Blend were discontinued in June 2007 so we augmented the series with Canada's Heavy Hardisty which has the same API as Lloyd Blend.
} 
statistic, $R_{2 T}$, and the one-sided Wald test statistic, $R_{1 T}$ (part 3). Both tests clearly indicate that we can strongly reject the null of unit root at the 1 per cent level. Thus, we can conclude with confidence that the Sahara-Maya price differential does not have a unit root but contains threshold effects.

The OLS estimates of the TAR model of lag order $p=5$ and delay parameter $m=2$ are shown in Table 3. The threshold estimate is $\$ 11.90$. In other words, the TAR split the regression function into two regimes (Regime 1 and Regime 2) depending on whether the lagged value of the differential lies below or above $\$ 11.90$. The first regime occurs when the lagged oil price differential is less than or equal to $\$ 11.90$. The first regime contains 74.5 per cent of observations. The second regime, on the other hand, occurs when the oil price differential has exceeded the $\$ 11.90$ mark. The TAR estimates reveal some interesting results. They indicate the existence of an asymmetric adjustment process. While in the second regime there is evidence of a statistically significant reverting dynamics to the long-run equilibrium as implied by the statistically significant coefficient on the lagged level, there is no evidence of such reversion in the first regime. These results are confirmed by the individual one-sided Wald test statistics, $t_{1}$ and $t_{2}$ reported in Table 2 (section 4 ). They show the existence of a partial unit root, i.e. oil price differentials process has a unit root process in one regime, but is stationary in the other. Specifically, the one-sided Wald test statistic $t_{1}$, indicate that we cannot reject the null of unit root in favour of the alternative of stationarity in Regime 1 . The one-sided Wald test statistic $t_{2}$, however, suggests that we can reject the null of unit root in favour of the alternative of stationarity in Regime 2. The results taken together suggest that the dynamics of oil price differentials are different depending whether the oil price differential is below or above the estimated threshold. In the first regime, oil price differentials follow a random walk process. On the other hand, in Regime 2, oil price differentials exhibit a stationary behaviour.

It is interesting to note that both the coefficients on lagged levels and the coefficients on lagged differences are responsible for the non-linearity in our model. This can be tested by a joint Wald test for the equality of coefficients across the two regimes. As can be seen from Table 3, the null that the coefficients on $y_{t-1}$ are the same can be rejected at the 1 per cent level, suggesting the difference between the two regimes is due to stationarity versus unit root. The Wald tests for equality of coefficients on the autoregressive coefficients also indicate that there are major differences in the coefficients on $\Delta y_{t-i}$ for many lags $(1,3,4,5)$ suggesting that the differences in the autoregressive coefficients are also contributing to the non-linear dynamics.

We subtract the price differential from the estimated threshold over the sample period. This allows us to split observations according to the two regimes, as shown in Figure 2. 
Specifically, positive values identify the stationary regime while negative values identify the unit root regime. It is interesting to note that most of the observations in the stationary regime are concentred in last years of the sample. This is expected as most of the large variations in oil price differentials occurred in the last three years of the sample.

For robustness, in Tables 4 and 5 we report the results for the Bonny-Maya price differential. The results paint a very similar picture to that of the Sahara-Maya price differential where unit root tests such as the ADF cannot reject the null of unit root at the 1 per cent level while the threshold stationary test rejects strongly the null of unit root at the 1 per cent level. The sup-Wald statistic and the bootstrap $p$-values for the stationary and unit root cases suggest that we are able to reject strongly the null of linearity, indicating the existence of threshold effects. Specifically, the TAR splits the regression function into two regimes depending on whether the lagged value is below or above $\$ 13.30$. The TAR estimates indicate the existence of an asymmetric adjustment process. As before, while in the second regime there is evidence of a statistically significant reverting dynamics to the long-run equilibrium as implied by the statistically significant coefficient on the lagged differential, there is no evidence of such reversion in the first regime. These results are confirmed by the individual one-sided Wald test statistics, $t_{1}$ and $t_{2}$ reported in Table 4 (section 4 ). The Wald tests for equality of coefficients on the autoregressive coefficients indicate that both lagged differential and differences in the autoregressive coefficients (lags 3, 5, and 6) are contributing to the nonlinear dynamics.

\subsection{Price Differentials between Crude Oils of Similar Quality}

Tables 6 and 7 report the results for the Sahara-Bonny (light/light) price differential. As expected, the conventional unit root tests suggest that the oil price differential follows a stationary process and hence we do not carry the threshold unit root test. What is interesting to note, however, is that the sup-Wald statistic rejects the null of linearity in favour of the threshold model. The TAR estimates provide support for these threshold effects. Although both regimes show error correction dynamics (the coefficients on the lagged level are both significant), these error-correction dynamics become stronger if the differential exceeds the $\$ 0.25$ threshold. The Wald tests for equality of coefficients indicate that we can reject the null that coefficients on the lagged level are equal. The individual Wald test statistics indicate that the non-linear dynamics are driven by the differences in the coefficients on $y_{t-1}$ and not by the lagged differences. As before, we subtract the price differential from the estimated threshold over the sample period. This allows us to split observations according to the two regimes as shown in Figure 3. It is interesting to note that most of the observations in the high 
error-correcting regime are concentred in last years of the sample although the year 20012002 also contains such observations.

Tables 8 and 9 report the results for the Maya-Lloyd Blend (heavy/heavy) price differential. As expected, the conventional unit root tests suggest that that the price differential follows a stationary process. As before, the sup-Wald statistic indicates the rejection of the null of linearity in favour of the threshold model. The TAR estimates provide support for these threshold effects. Although both regimes show error correction dynamics (the coefficients on the lag differentials are both significant), these error-correction dynamics become stronger if the differential exceeds $\$ 0.32$. The Wald tests for equality of coefficients indicate that we can reject the null that coefficients on the lagged level are equal and that the dynamics are driven by the differences in the coefficients on $y_{t-1} \cdot{ }^{10}$

\subsection{Price Differentials between Crude Oils one of which is Linked to an Active}

\section{Futures Market}

Tables 10 and 11 reports the price differential between WTI and Maya. As can be seen from Table 10, the tests for unit root indicate that we cannot reject the null of unit root at the 5 per cent level. Based on the sup-Wald statistic, we are able to strongly reject the null of linearity in favour of a threshold model based on both bootstrap $p$-values. Both the two-sided Wald test statistic, $R_{2 T}$, and the one-sided Wald test statistic, $R_{1 T}$ indicate that we can strongly reject the null of unit root at the 1 per cent level. Thus, we can conclude with that oil price differential does not contain a unit root. The OLS estimates of the TAR model of lag order $p=3$ and delay parameter $m=3$ are shown in Table 11 . The threshold estimate is $\$ 11.70$. The TAR estimates reveal similar dynamics to the case of Bonny-Maya or Sahara-Maya, indicating the existence of an asymmetric adjustment process. While in the second regime there is evidence of a statistically significant reverting dynamics to the long-run equilibrium as implied by the statistically significant coefficient on the lagged differential, there is no evidence of such reversion in the first regime. These results are confirmed by the individual one-sided Wald test statistics, $t_{1}$ and $t_{2}$ reported in Table 11, where they reveal the existence of a partial unit root, i.e. the oil price differentials process has a unit root process in one regime, but is stationary in the other. For robustness, we also report in Table 12 and 13 the results for WTILloyd Blend. The results are very similar to the previous ones and hence are not discussed here.

\footnotetext{
${ }^{10}$ For robustness, we also examined the Maya-Saudi Arabia heavy oil price differential. As expected, we find evidence of stationarity but unlike the Maya-Lloyd Blend price differential, we were not able to reject the null of threshold effects.
} 
Table 14 reports the results for the price differential between WTI and Sahara (both light crude oils). As expected, the conventional unit root tests suggest that we can reject the null of unit root at the 1 per cent level for both price differentials. What is interesting, though, that unlike the case of Sahara-Bonny, we do not find any significant threshold effects, indicating that the adjustment process is linear. For completeness, we also report the results for WTI and Bonny. As expected, the conventional unit root tests suggest that we can reject the null of unit root at the 1 per cent level for both price differentials (Table 15). However, unlike the price differential between WTI and Sahara, we find evidence of threshold effects but, as can be seen from Table 16, these threshold effects are driven by significant differences in the constant term rather than differences in lagged levels. In other words, the dynamics of adjustment are similar in both regimes and do not depend on the price differential reaching a certain threshold.

The absence of threshold effects in the adjustment dynamics may indicate that price differentials between pairs of crude oils of similar quality and one of which is linked to a highly tradable contract reduces transaction costs by facilitating arbitrage and hence the adjustment process is instantaneous. This tradability aspect, however, does not change the dynamics when crude oils of different quality are involved. ${ }^{11}$

\subsection{Price Differentials between Crude Oils both with Tradable Paper Contract}

Finally, we examine the price differential between crude oils both of which are linked to a liquid tradable paper contract. We start first with the WTI and Brent price differential. As expected, the conventional unit root tests, such as the ADF tests, suggest strong evidence of stationarity. Also, as expected, we find no evidence of threshold effects indicating that the adjustment process is linear (see Table 17). We next examine the price differential between WTI and Dubai, crude oils of different quality. As can be seen from Table 18, we can reject the null of unit root. But unlike the previous case, we find evidence of threshold effects, although the non-linear dynamics are driven by the change in the lagged difference (at lags 2 and 3) rather than differences in the adjustment dynamics (see Table 19).

\subsection{Discussion of the Empirical Results}

\footnotetext{
${ }^{11}$ This conclusion, however, cannot be generalized. For instance, we examined the price differentials between Sahara (light) and Dubai (medium/sour). Dubai is not linked to an active futures market but it is the only available crude that is considered medium (its API is much higher than Maya) and at the same time has a paper contract that is traded over the counter (OTC). Although these crude oils are of different quality, the conventional unit root tests suggest strong evidence of stationarity. Interestingly, the null of linearity in favour of a threshold model cannot be rejected at conventional levels indicating that adjustment to long-run equilibrium is linear. Such evidence strengthens the conclusions that price differentials involving a crude oil with a tradable paper contract can affect price differentials even across crude oils of different quality.
} 
Based on the above results, it is possible to draw the following conclusions. Firstly, the price differential between crude oils of similar quality shows a strong evidence of stationarity. Secondly, there is strong evidence that the adjustment process between crude oils of similar quality is very different from that of crude oils of different quality. Our findings indicate that oil price differentials between crude oils of different quality do not have a unit root. The results, however, suggest that there are threshold effects in the dynamics of oil price differentials such that the adjustment process to the long-term equilibrium follows a nonlinear process. For price differentials between crude oils with very different qualities, reversion to long-run equilibrium occurs only when these price differentials have risen above a certain threshold. These threshold effects may indicate the existence of transaction costs in arbitraging crude oil with different qualities and/or transaction costs related to refining bottlenecks. Specifically, it might be the case that refineries would be willing to take delivery and process heavy crude only if the discount to light crudes is large enough to compensate them for running their refineries on less suitable crudes. Thirdly, the existence of a highly liquid futures market do not alter the first and second conclusion but can change the dynamics of some crude oil price differentials, especially for crude oils of similar quality by eliminating the threshold effects. This also extends to crude oils of different quality. For instance, in the case of the price differential between WTI and Dubai, we find evidence of threshold effects but these effects are driven by the lagged differences rather than differences in errorcorrection dynamics. The absence of threshold effects may indicate that a crude oil with a highly tradable contract reduces transaction costs by facilitating arbitrage.

\section{Conclusion}

One of the very interesting features of the oil pricing system in recent years has been the wide variations in oil price differentials, with the differential reaching very high levels in many instances. This has raised the issue of whether the oil market should be treated as one great pool. Using a TAR model suggested by Caner and Hansen (2001) and weekly data on various pairs of oil price differentials, our findings suggest that oil price differentials follow a stationary process even for pairs of crude oil with very different qualities. As such, the different oil markets are linked and thus at the very general level, our findings provide support for the 'one great pool' or 'globalization' hypotheses. However, our findings also suggest that the price differentials between various pairs of crude oil follow very different dynamics depending on a number of features, such as the types of crude oil and whether a crude oil is linked to an active futures market. For instance, our findings suggest that the adjustment process between crude oils of similar quality is very different from that of crude oils of different quality. While markets for different types of crude oil move together, they are not fully integrated in every time period. Our evidence of non-linearity in the adjustment 
process suggests the presences of transaction costs and/or the absence of riskless arbitrage which may cause oil markets to wander off from each other, but not without bounds. These differences in the dynamics of crude oil price differentials suggest that within the one great oil market pool, oil markets are not integrated in every time period and that the regional influences have not yet disappeared. In addition, although our results indicate that the presence of an active futures market has helped make some distant markets more unified, arbitrage across the different markets is not costless or risk-free. 


\section{References}

Adelman, M. A. (1984). 'International Oil Agreements'. The Energy Journal 5(3): 1-9.

Alizadeh A, N., and Nomikos, N. K. (2004). 'Cost of Carry, Causality and Arbitrage between

Oil Futures and Tanker Freight Markets'. Transportation Research Part E, Logistics and Transportation Review 40, No. 4: 297-317.

Bacon, R., and Tordo, S. (2005). Crude Oil Price Differentials and Differences in Oil Qualities: A Statistical Analysis. Energy Sector Management Assistance Programme (ESMAP) Technical Paper 081. Washington: World Bank.

Balke, N. S., and Fomby, T. B. (1997). 'Threshold Cointegration'. International Economic Review 38: 627-45.

Caner, M., and Hansen, B. E. (2001). 'Threshold Autoregression with a Unit Root'. Econometrica 69: 1555-96.

Davies, R. B. (1987). 'Hypothesis Testing When a Nuisance Parameter is Present Only Under the Alternative'. Biometrika 74: 33-43.

Dickey, D. A., and Fuller, W. A., (1979). 'Distribution of the Estimators for Autoregressive Time Series with a Unit Root'. Journal of the American Statistical Association 74, 427-31.

Energy Intelligence Group (2006). The 2006 International Crude Oil Market Handbook. New York: Energy Intelligence Group.

Fattouh, B. (2006). 'The Origins and Evolution of the Current International Oil Pricing System: A Critical Assessment'. Chapter 3 in R. Mabro (ed.), Oil in the Twenty-First Century: Issues, Challenges, and Opportunities. Oxford: Oxford University Press.

Fattouh, B. (2007). 'WTI Benchmark Temporarily Breaks Down: Is It Really a Big Deal?' Middle East Economic Survey 49, No 20, 14 May.

Gülen, S. G., (1999). 'Regionalization in the World Crude Oil Market: Further Results'. The Energy Journal 20(1): 125-39.

Gülen, S. G. (1997). 'Regionalization in the World Crude Oil Market'. The Energy Journal 18(2): 109-26.

Hansen, B. E. (1996). 'Inference When a Nuisance Parameter is not Identified Under the Null Hypothesis'. Econometrica 64: 413-30.

Horsnell, P., and Mabro, R. (1993). Oil Markets and Prices: The Brent Market and the Formation of World Oil Prices. Oxford: Oxford University Press. 
Kinnear, K. (2002). 'The Brent WTI Arbitrage: Linking the World's Key Crudes'. Energy in the News, Vol. 2, 2001

Kleit, A. N. (2001). 'Are Regional Oil Markets Growing Closer Together? An Arbitrage Cost Approach'. The Energy Journal 22(1): 1-15.

Milonas, N., and Henker, T. (2001). 'Price Spread and Convenience Yield Behaviour in the International Oil Market'. Applied Financial Economics 11: 23-36.

Ng, S., and Perron, P. (2001). 'Lag Length Selection and the Construction of Unit Root Test with Good Size and Power'. Econometrica 69, 1519-54.

Phillips, P., and Perron, P. (1988): 'Testing for a Unit Root in Time Series Regressions'. Biometrica 75: 335-46.

Weiner, R. J. (1991). 'Is the World Oil Market “One Great Pool?”' The Energy Journal 12(3): 95-107. 
Table 1: Pairs of Crude Oil Price Differentials Analysed

\begin{tabular}{|l|l|l|}
\hline Pairs of Crude Oils & Futures Market & Characteristics \\
\hline Sahara-Maya & Non-Active/Non-Active & Light/Heavy \\
\hline Bonny-Maya & Non-Active/Non-Active & Light/Heavy \\
\hline Bonny-Sahara & Non-Active/Non-Active & Light/Light \\
\hline Maya-Lloyd Blend & Non-Active/Non Active & Heavy/Heavy \\
\hline WTI-Maya & Non Active/Active & Light/Heavy \\
\hline WTI-Lloyd Blend & Non Active/ Active & Light/Heavy \\
\hline WTI-Sahara & Active/ Non Active & Light/Light \\
\hline WTI-Bonny & Active/Non-Active & Light/Light \\
\hline WTI-Brent & Active/Active & Light/Light \\
\hline WTI-Dubai & Active/Active & Light/Heavy \\
\hline
\end{tabular}


Table 2: Sahara-Maya Price Differential

\begin{tabular}{|c|c|c|}
\hline \multicolumn{3}{|c|}{ 1. UNIT Root Tests ${ }^{1}$} \\
\hline $\operatorname{ADF}(5)=-1.439$ & $\mathrm{PP}(5)=-1.734$ & $A D F-G L S(5)=-1.095$ \\
\hline \multicolumn{3}{|c|}{ 2. Wald Tests for Threshold Effect ${ }^{2}$} \\
\hline sup-Wald Test $(2)=43.4$ & Stationary $p$-value $=0.00$ & Unit Root $p$-value $=0.00$ \\
\hline \multicolumn{3}{|c|}{ 3. Two-Sided Wald Test for Unit Root ${ }^{3}$} \\
\hline \multirow{2}{*}{\multicolumn{3}{|c|}{\begin{tabular}{l|l} 
Asym $p$-value $=0.00$ & Bootstrap $p$-value $=0.00$ \\
One-Sided Wald Test for Unit Root $^{3}$
\end{tabular}}} \\
\hline & & \\
\hline Wald Stat $=23.6$ & Asym $p$-value $=0.00$ & Bootstrap $p$-value $=0.00$ \\
\hline \multicolumn{3}{|c|}{ 4. Unit Root Tests for Individual Regimes ${ }^{4}$} \\
\hline \multicolumn{3}{|c|}{$t_{1}$ Test for Stationarity } \\
\hline$t$-Stat $=1.39$ & Asym $p$-value $=0.448$ & Bootstrap $p$-value $=0.749$ \\
\hline \multicolumn{3}{|c|}{$t_{2}$ Test for Stationarity } \\
\hline$t-\mathrm{Stat}=4.65$ & Asym $p$-value $=0.000$ & Bootstrap $p$-value $=0.000$ \\
\hline
\end{tabular}

\section{Notes:}

1. ADF refers to Augmented Dickey-Fuller (1979) test. The lag number (in parenthesis) selected using the AIC criterion. PP refers to Philips-Perron (1988) test statistics. The lag number (in parenthesis) selected using the Newey-West criterion. The critical values for both the ADF and Philips-Perron tests are equal to $-3.46,-2.87$, and -2.57 for the $1 \%, 5 \%$, and $10 \%$ level of significance, respectively. We also report the $A D F-G L S$ for the case of only a constant in the deterministic component developed by $\mathrm{Ng}$ and Perron (2001). The optimal lag selection has been carried using the modified AIC criterion suggested by $\mathrm{Ng}$ and Perron (2001). The $1 \%, 5 \%$, and $10 \%$ critical values for the $A D F-G L S$ tests are $-2.58,-1.98$, and -1.66 , respectively.

2. The delay order in parentheses. The $p$-values for the threshold for the unrestricted and unit root restriction cases were obtained by 1000 bootstrap replications. The Wald statistic tests the null of linearity against the alternative of threshold effect in the estimated model. The results reported in all the tables correspond to a trimming region (which defines the bounds $\pi_{1}$ and $\pi_{2}$ within which the threshold falls) given by the values $[0.10,0.90]$. The results (available upon request from the author) are robust to different trimming regions and higher or lower lag length. We have used Gauss for all estimations reported in this paper.

3. The $p$-values for the threshold and unit root tests were obtained by 1000 bootstrap replications. The two-sided $R_{2}$ and one-sided $R_{1}$ Wald statistics test the null of unit root against the alternative of stationary or partial unit root.

4. The $p$-values for the threshold and unit root tests were obtained by 1000 bootstrap replications. The asymptotic critical values for the $10 \%, 5 \%$, and $1 \%$ are $2.97,3.26$, and 3.82 respectively. The $t_{1}$ statistic tests the null of unit root against the alternative that the first regime is stationary. The $t_{2}$ statistic tests the null of unit root against the alternative that the second regime is stationary. 
Table 3: Estimation of Threshold Autoregressive Model (Sahara-Maya)

$($ Lag Order $=5 ;$ Delay Parameter $=2 ;$ Threshold Estimate $=\$ \mathbf{1 1 . 9 0})$

\begin{tabular}{|c|c|c|c|}
\hline & $\begin{array}{l}\text { Column A } \\
\text { Regime } 1\end{array}$ & $\begin{array}{l}\text { Column B } \\
\text { Regime } 2\end{array}$ & $\begin{array}{l}\text { Column C } \\
\text { Wald Tests for Equality in } \\
\text { Individual Coefficients }\end{array}$ \\
\hline Intercept & $\begin{array}{l}0.141 \\
(0.093)\end{array}$ & $\begin{array}{l}3.30 \\
(0.712)\end{array}$ & $\begin{array}{l}19.4 \\
\text { Bootstrap } p \text {-value }=0.00\end{array}$ \\
\hline $\mathrm{y}_{t-1}$ & $\begin{array}{l}-0.022 \\
(0.016)\end{array}$ & $\begin{array}{l}-0.229 \\
(0.049)\end{array}$ & $\begin{array}{l}15.9 \\
\text { Bootstrap } p \text {-value }=0.00\end{array}$ \\
\hline$\Delta \mathrm{y}_{t-1}$ & $\begin{array}{l}0.097 \\
(0.052)\end{array}$ & $\begin{array}{l}0.360 \\
(0.077)\end{array}$ & $\begin{array}{l}7.93 \\
\text { Bootstrap } p \text {-value }=0.05\end{array}$ \\
\hline$\Delta \mathrm{y}_{t-2}$ & $\begin{array}{l}-0.058 \\
(0.051)\end{array}$ & $\begin{array}{l}-0.091 \\
(0.075)\end{array}$ & $\begin{array}{l}0.131 \\
\text { Bootstrap } p \text {-value }=0.825\end{array}$ \\
\hline$\Delta y_{t-3}$ & $\begin{array}{l}-0.132 \\
(0.050)\end{array}$ & $\begin{array}{l}0.135 \\
(0.076)\end{array}$ & $\begin{array}{l}8.45 \\
\text { Bootstrap } p \text {-value }=0.04\end{array}$ \\
\hline$\Delta \mathrm{y}_{t-4}$ & $\begin{array}{l}0.122 \\
(0.050)\end{array}$ & $\begin{array}{l}-0.124 \\
(0.073)\end{array}$ & $\begin{array}{l}7.57 \\
\text { Bootstrap } p \text {-value }=0.04\end{array}$ \\
\hline$\Delta \mathrm{y}_{t-5}$ & $\begin{array}{l}-0.164 \\
(0.050)\end{array}$ & $\begin{array}{l}0.153 \\
(0.074)\end{array}$ & $\begin{array}{l}12.4 \\
\text { Bootstrap } p \text {-value }=0.00\end{array}$ \\
\hline
\end{tabular}

Regime 1 contains $74.5 \%$ of the observations. 
Table 4: Bonny-Maya Price Differential

\begin{tabular}{|c|c|c|}
\hline \multicolumn{3}{|c|}{ 1. UNIT Root Tests ${ }^{1}$} \\
\hline $\mathrm{ADF}(8)=-0.941$ & $\mathrm{PP}(5)=-1.585$ & $A D F-G L S(8)=-0.561$ \\
\hline \multicolumn{3}{|c|}{ 2. Wald Tests for Threshold Effect ${ }^{2}$} \\
\hline sup-Wald Test $(2)=60.4$ & Stationary $p$-value $=0.00$ & Unit Root $p$-value $=0.00$ \\
\hline \multicolumn{3}{|c|}{ 3. Two-Sided Wald Test for Unit Root ${ }^{3}$} \\
\hline \multirow{2}{*}{\multicolumn{3}{|c|}{ One-Sided Wald Test for Unit Root $^{3}$}} \\
\hline & & \\
\hline Wald Stat $=36.3$ & Asym $p$-value $=0.00$ & Bootstrap $p$-value $=0.00$ \\
\hline \multicolumn{3}{|c|}{ 4. Unit Root Tests for Individual Regimes ${ }^{4}$} \\
\hline \multicolumn{3}{|c|}{$t_{1}$ Test for Stationarity } \\
\hline$t-$ Stat $=0.751$ & Asym $p$-value $=0.615$ & Bootstrap $p$-value $=0.915$ \\
\hline \multicolumn{3}{|c|}{$t_{2}$ Test for Stationarity } \\
\hline$t$-Stat $=5.98$ & Asym $p$-value $=0.000$ & Bootstrap $p$-value $=0.000$ \\
\hline
\end{tabular}

Notes: See Table 1. 
Table 5: Estimation of Threshold Autoregressive Model (Bonny-Maya)

$($ Lag Order $=8 ;$ Delay Parameter $=2 ;$ Threshold Estimate $=\$$ 13.30 $)$

\begin{tabular}{|c|c|c|c|}
\hline & $\begin{array}{l}\text { Column A } \\
\text { Regime } 1\end{array}$ & $\begin{array}{l}\text { Column B } \\
\text { Regime } 2\end{array}$ & $\begin{array}{l}\text { Column C } \\
\text { Wald Tests for Equality in } \\
\text { Individual Coefficients }\end{array}$ \\
\hline Intercept & $\begin{array}{l}0.085 \\
(0.092)\end{array}$ & $\begin{array}{l}5.85 \\
(0.982)\end{array}$ & $\begin{array}{l}34.2 \\
\text { Bootstrap } p \text {-value }=0.00\end{array}$ \\
\hline $\mathrm{y}_{t-1}$ & $\begin{array}{l}-0.011 \\
(0.015)\end{array}$ & $\begin{array}{l}-0.382 \\
(0.063)\end{array}$ & $\begin{array}{l}31.7 \\
\text { Bootstrap } p \text {-value }=0.00\end{array}$ \\
\hline$\Delta \mathrm{y}_{t-1}$ & $\begin{array}{l}0.002 \\
(0.054)\end{array}$ & $\begin{array}{l}0.213 \\
(0.087)\end{array}$ & $\begin{array}{l}4.14 \\
\text { Bootstrap } p \text {-value }=0.159\end{array}$ \\
\hline$\Delta \mathrm{y}_{t-2}$ & $\begin{array}{l}-0.097 \\
(0.004)\end{array}$ & $\begin{array}{l}0.111 \\
(0.084)\end{array}$ & $\begin{array}{l}4.57 \\
\text { Bootstrap } p \text {-value }=0.154\end{array}$ \\
\hline$\Delta \mathrm{y}_{t-3}$ & $\begin{array}{l}-0.130 \\
(0.048)\end{array}$ & $\begin{array}{l}0.200 \\
(0.084)\end{array}$ & $\begin{array}{l}11.6 \\
\text { Bootstrap } p \text {-value }=0.01\end{array}$ \\
\hline$\Delta y_{t-4}$ & $\begin{array}{l}0.022 \\
(0.048)\end{array}$ & $\begin{array}{l}-0.010 \\
(0.083)\end{array}$ & $\begin{array}{l}0.121 \\
\text { Bootstrap } p \text {-value }=0.814\end{array}$ \\
\hline$\Delta y_{t-5}$ & $\begin{array}{l}-0.168 \\
(0.047)\end{array}$ & $\begin{array}{l}0.173 \\
(0.086)\end{array}$ & $\begin{array}{l}11.9 \\
\text { Bootstrap } p \text {-value }=0.017\end{array}$ \\
\hline$\Delta \mathrm{y}_{t-6}$ & $\begin{array}{l}-0.199 \\
(0.050)\end{array}$ & $\begin{array}{l}0.085 \\
(0.074)\end{array}$ & $\begin{array}{l}10 \\
\text { Bootstrap } p \text {-value }=0.018\end{array}$ \\
\hline$\Delta y_{t-7}$ & $\begin{array}{l}0.088 \\
(0.054)\end{array}$ & $\begin{array}{l}0.027 \\
(0.066)\end{array}$ & $\begin{array}{l}0.514 \\
\text { Bootstrap } p \text {-value }=0.615\end{array}$ \\
\hline$\Delta \mathrm{y}_{t-8}$ & $\begin{array}{l}-0.133 \\
(0.053)\end{array}$ & $\begin{array}{l}0.002 \\
(0.065)\end{array}$ & $\begin{array}{l}2.56 \\
\text { Bootstrap } p \text {-value }=0.263\end{array}$ \\
\hline
\end{tabular}

Regime 1 contains $76.2 \%$ of the observations. 
Table 6: Sahara-Bonny Price Differential

\begin{tabular}{|l|l|l|}
\hline \multicolumn{3}{|c|}{ 1. UNIT Root Tests } \\
\hline ADF (7) $=-3.046$ & PP (5) $=-7.600$ & $A D F-G L S(7)=-2.732$ \\
\hline \multicolumn{3}{|c|}{ 2. Wald Tests for Threshold Effect ${ }^{2}$} \\
\hline \multicolumn{3}{|c|}{} \\
\hline sup-Wald Test (7)=111 & Stationary $p$-value $=0.00$ & Unit Root $p$-value $=0.00^{2}$
\end{tabular}

Notes: See Table 1. 
Table 7: Estimation of Threshold Autoregressive Model (Sahara-Bonny)

$($ Lag Order $=7$; Delay Parameter $=7$; Threshold Estimate $=\$ \mathbf{\$ 0 . 2 5})$

\begin{tabular}{|c|c|c|c|}
\hline & $\begin{array}{l}\text { Column A } \\
\text { Regime } 1\end{array}$ & $\begin{array}{l}\text { Column B } \\
\text { Regime } 2\end{array}$ & $\begin{array}{l}\text { Column C } \\
\text { Wald Tests for Equality in } \\
\text { Individual Coefficients }\end{array}$ \\
\hline Intercept & $\begin{array}{l}-0.015 \\
(0.020)\end{array}$ & $\begin{array}{l}0.182 \\
(0.066)\end{array}$ & $\begin{array}{l}8.18 \\
\text { Bootstrap } p \text {-value }=0.195\end{array}$ \\
\hline $\mathrm{y}_{t-1}$ & $\begin{array}{l}-0.052 \\
(0.032)\end{array}$ & $\begin{array}{l}-0.871 \\
(0.172)\end{array}$ & $\begin{array}{l}21.9 \\
\text { Bootstrap } p \text {-value }=0.01\end{array}$ \\
\hline$\Delta \mathrm{y}_{t-1}$ & $\begin{array}{l}-0.132 \\
(0.062)\end{array}$ & $\begin{array}{l}0.048 \\
(0.160)\end{array}$ & $\begin{array}{l}1.10 \\
\text { Bootstrap } p \text {-value }=0.535\end{array}$ \\
\hline$\Delta \mathrm{y}_{t-2}$ & $\begin{array}{l}-0.113 \\
(0.056)\end{array}$ & $\begin{array}{l}0.405 \\
(0.173)\end{array}$ & $\begin{array}{l}8.15 \\
\text { Bootstrap } p \text {-value }=0.08\end{array}$ \\
\hline$\Delta \mathrm{y}_{t-3}$ & $\begin{array}{l}-0.111 \\
(0.054)\end{array}$ & $\begin{array}{l}0.133 \\
(0.167)\end{array}$ & $\begin{array}{l}1.94 \\
\text { Bootstrap } p \text {-value }=0.373\end{array}$ \\
\hline$\Delta \mathrm{y}_{t-4}$ & $\begin{array}{l}-0.065 \\
(0.052)\end{array}$ & $\begin{array}{l}-0.360 \\
(0.161)\end{array}$ & $\begin{array}{l}3.02 \\
\text { Bootstrap } p \text {-value }=0.248\end{array}$ \\
\hline$\Delta \mathrm{y}_{t-5}$ & $\begin{array}{l}-0.058 \\
(0.051)\end{array}$ & $\begin{array}{l}-0.262 \\
(0.148)\end{array}$ & $\begin{array}{l}1.67 \\
\text { Bootstrap } p \text {-value }=0.38\end{array}$ \\
\hline$\Delta \mathrm{y}_{t-6}$ & $\begin{array}{l}-0.056 \\
(0.055)\end{array}$ & $\begin{array}{l}-0.060 \\
(0.087)\end{array}$ & $\begin{array}{l}0.001 \\
\text { Bootstrap } p \text {-value }=0.979\end{array}$ \\
\hline$\Delta y_{t-7}$ & $\begin{array}{l}-0.247 \\
(0.065)\end{array}$ & $\begin{array}{l}-0.053 \\
(0.058)\end{array}$ & $\begin{array}{l}4.82 \\
\text { Bootstrap } p \text {-value }=0.119\end{array}$ \\
\hline
\end{tabular}

Regime 1 contains $74.4 \%$ of the observations. 
Table 8: Maya-Lloyd Blend Price Differential

\begin{tabular}{|l|l|l|}
\hline \multicolumn{3}{|c|}{ 1. UNIT Root Tests $^{1}$} \\
\hline ADF (1) $=-3.971$ & PP $(5)=-4.618$ & $A D F-G L S(1)=-3.506$ \\
\hline \multicolumn{3}{|c|}{ 2. Wald Tests for Threshold Effect ${ }^{2}$} \\
\hline \multicolumn{3}{|c|}{} \\
\hline sup-Wald Test $(1)=38.7$ & Stationary $p$-value $=0.00$ & Unit Root $p$-value $=0.00^{2}$
\end{tabular}

Notes: See Table 1. 
Table 9: Estimation of Threshold Autoregressive Model (Maya-Lloyd Blend)

$($ Lag Order $=1 ;$ Delay Parameter $=1 ;$ Threshold Estimate $=\$ 0.32)$

\begin{tabular}{|l|l|l|l|}
\hline & $\begin{array}{l}\text { Column A } \\
\text { Regime 1 }\end{array}$ & $\begin{array}{l}\text { Column B } \\
\text { Regime 2 }\end{array}$ & $\begin{array}{l}\text { Column C } \\
\text { Wald Tests for Equality in } \\
\text { Individual Coefficients }\end{array}$ \\
\hline Intercept & $\begin{array}{l}0.068 \\
(0.008)\end{array}$ & -0.648 & 7.17 \\
& $(0.255)$ & Bootstrap $p$-value $=0.123$ \\
\hline $\mathrm{y}_{t-1}$ & -0.047 & -0.871 & 15.5 \\
& $(0.017)$ & $(0.208)$ & Bootstrap $p$-value $=0.01$ \\
\hline$\Delta \mathrm{y}_{t-1}$ & -0.084 & -0.287 & 2.05 \\
& $(0.044)$ & $(0.134)$ & Bootstrap $p$-value $=0.339$ \\
\hline
\end{tabular}

Regime 1 contains $84.5 \%$ of the observations. 
Table 10: WTI-Maya Price Differential

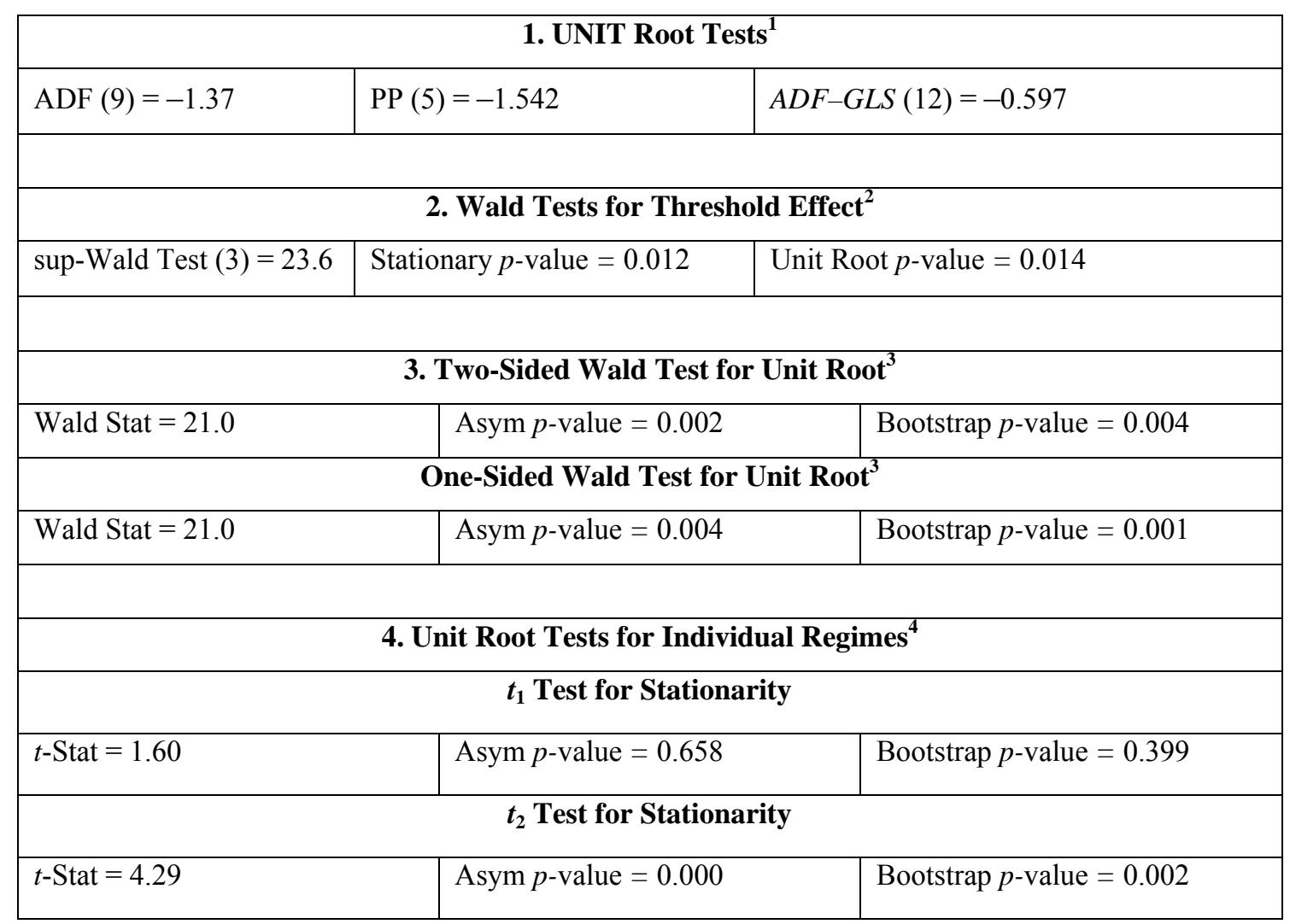

Notes: See Table 1. 
Table 11: Estimation of Threshold Autoregressive Model (WTI-Maya)

$($ Lag Order $=3$; Delay Parameter $=3 ;$ Threshold Estimate $=\$$ 11.70 $)$

\begin{tabular}{|l|l|l|l|}
\hline & $\begin{array}{l}\text { Column A } \\
\text { Regime 1 }\end{array}$ & $\begin{array}{l}\text { Column B } \\
\text { Regime 2 }\end{array}$ & $\begin{array}{l}\text { Column C } \\
\text { Wald Tests for Equality in } \\
\text { Individual Coefficients }\end{array}$ \\
\hline Intercept & 0.226 & 2.19 & 14.2 \\
& $(0.135)$ & $(1.27)$ & Bootstrap $p$-value $=0.014$ \\
\hline $\mathrm{y}_{t-1}$ & -0.030 & -0.144 & 8.56 \\
& $(0.019)$ & $(0.033)$ & Bootstrap $p$-value $=0.048$ \\
\hline$\Delta \mathrm{y}_{t-1}$ & -0.121 & -0.074 & 0.280 \\
& $(0.060)$ & $(0.066)$ & Bootstrap $p$-value $=0.752$ \\
\hline$\Delta \mathrm{y}_{t-2}$ & -0.145 & 0.0871 & 6.68 \\
& $(0.062)$ & $(0.064)$ & Bootstrap $p$-value $=0.055$ \\
\hline$\Delta \mathrm{y}_{t-3}$ & 0.039 & 0.042 & 0.001 \\
& $(0.059)$ & $(0.060)$ & Bootstrap $p$-value $=0.981$ \\
\hline
\end{tabular}

Regime 1 contains $73.5 \%$ of the observations. 
Table 12: WTI-Lloyd Blend Price Differential

\begin{tabular}{|c|c|c|}
\hline \multicolumn{3}{|c|}{ 1. UNIT Root Tests ${ }^{1}$} \\
\hline $\mathrm{ADF}(7)=-1.321$ & $\mathrm{PP}(5)=-2.009$ & $A D F-G L S(7)=-0.787$ \\
\hline \multicolumn{3}{|c|}{ 2. Wald Tests for Threshold Effect ${ }^{2}$} \\
\hline sup-Wald Test $(2)=57.5$ & Stationary $p$-value $=0.00$ & Unit Root $p$-value $=0.00$ \\
\hline \multicolumn{3}{|c|}{ 3. Two-Sided Wald Test for Unit Root ${ }^{3}$} \\
\hline \multirow{2}{*}{\multicolumn{3}{|c|}{ One-Sided Wald Test for Unit Root ${ }^{3}$}} \\
\hline & & \\
\hline Wald Stat $=16.7$ & Asym $p$-value $=0.010$ & Bootstrap $p$-value $=0.025$ \\
\hline \multicolumn{3}{|c|}{ 4. Unit Root Tests for Individual Regimes ${ }^{4}$} \\
\hline \multicolumn{3}{|c|}{$t_{1}$ Test for Stationarity } \\
\hline$t$-Stat $=0.384$ & Asym $p$-value $=0.951$ & Bootstrap $p$-value $=0.745$ \\
\hline \multicolumn{3}{|c|}{$t_{2}$ Test for Stationarity } \\
\hline$t$-Stat $=4.07$ & Asym $p$-value $=0.004$ & Bootstrap $p$-value $=0.007$ \\
\hline
\end{tabular}

Notes: See Table 1. 
Table 13: Estimation of Threshold Autoregressive Model (WTI-Lloyd Blend)

$($ Lag Order $=7$; Delay Parameter $=2 ;$ Threshold Estimate $=\$ 14.70)$

\begin{tabular}{|c|c|c|c|}
\hline & $\begin{array}{l}\text { Column A } \\
\text { Regime } 1\end{array}$ & $\begin{array}{l}\text { Column B } \\
\text { Regime } 2\end{array}$ & $\begin{array}{l}\text { Column C } \\
\text { Wald Tests for Equality in } \\
\text { Individual Coefficients }\end{array}$ \\
\hline Intercept & $\begin{array}{l}0.128 \\
(0.227)\end{array}$ & $\begin{array}{l}2.71 \\
(0.675)\end{array}$ & $\begin{array}{l}13.1 \\
\text { Bootstrap } p \text {-value }=0.05\end{array}$ \\
\hline $\mathrm{y}_{t-1}$ & $\begin{array}{l}-0.010 \\
(0.028)\end{array}$ & $\begin{array}{l}-0.129 \\
(0.031)\end{array}$ & $\begin{array}{l}7.82 \\
\text { Bootstrap } p \text {-value }=0.09\end{array}$ \\
\hline$\Delta \mathrm{y}_{t-1}$ & $\begin{array}{l}-0.554 \\
(0.068)\end{array}$ & $\begin{array}{l}-0.079 \\
(0.057)\end{array}$ & $\begin{array}{l}28.1 \\
\text { Bootstrap } p \text {-value }=0.00\end{array}$ \\
\hline$\Delta \mathrm{y}_{t-2}$ & $\begin{array}{l}-0.335 \\
(0.073)\end{array}$ & $\begin{array}{l}0.170 \\
(0.056)\end{array}$ & $\begin{array}{l}29.5 \\
\text { Bootstrap } p \text {-value }=0.00\end{array}$ \\
\hline$\Delta \mathrm{y}_{t-3}$ & $\begin{array}{l}-0.139 \\
(0.070)\end{array}$ & $\begin{array}{l}0.008 \\
(0.059)\end{array}$ & $\begin{array}{l}5.66 \\
\text { Bootstrap } p \text {-value }=0.104\end{array}$ \\
\hline$\Delta \mathrm{y}_{t-4}$ & $\begin{array}{l}-0.074 \\
(0.068)\end{array}$ & $\begin{array}{l}-0.036 \\
(0.057)\end{array}$ & $\begin{array}{l}0.177 \\
\text { Bootstrap } p \text {-value }=0.792\end{array}$ \\
\hline$\Delta \mathrm{y}_{t-5}$ & $\begin{array}{l}-0.066 \\
(0.069)\end{array}$ & $\begin{array}{l}0.159 \\
(0.057)\end{array}$ & $\begin{array}{l}6.29 \\
\text { Bootstrap } p \text {-value }=0.078\end{array}$ \\
\hline$\Delta y_{t-6}$ & $\begin{array}{l}-0.103 \\
(0.067)\end{array}$ & $\begin{array}{l}-0.073 \\
(0.059)\end{array}$ & $\begin{array}{l}0.110 \\
\text { Bootstrap } p \text {-value }=0.823\end{array}$ \\
\hline$\Delta y_{t-7}$ & $\begin{array}{l}-0.141 \\
(0.062)\end{array}$ & $\begin{array}{l}-0.093 \\
(0.060)\end{array}$ & $\begin{array}{l}0.296 \\
\text { Bootstrap } p \text {-value }=0.720\end{array}$ \\
\hline
\end{tabular}

Regime 1 contains $72.6 \%$ of the observations. 
Table 14: WTI-Sahara Price Differential

\begin{tabular}{|l|l|l|}
\hline \multicolumn{3}{|c|}{ 1. UNIT Root Tests } \\
\hline ADF $(2)=-4.342$ & PP $(5)=-5.655$ & $A D F-G L S(7)=-3.284$ \\
\hline \multicolumn{3}{|c|}{ 2. Wald Tests for Threshold Effect ${ }^{2}$} \\
\hline \multicolumn{3}{|c|}{} \\
\hline sup-Wald Test $(2)=14.8$ & Stationary $p$-value $=0.119$ & Unit Root $p$-value $=0.141^{2}$
\end{tabular}

Notes: See Table 1. 
Table 15: WTI-Bonny Price Differential

\begin{tabular}{|c|c|c|}
\hline \multicolumn{3}{|c|}{ 1. UNIT Root Tests ${ }^{1}$} \\
\hline $\operatorname{ADF}(2)=-3.813$ & $\mathrm{PP}(5)=-5.294$ & $A D F-G L S(15)=-3.023$ \\
\hline \multicolumn{3}{|c|}{ 2. Wald Tests for Threshold Effect ${ }^{2}$} \\
\hline sup-Wald Test $(2)=18.8$ & Stationary $p$-value $=0.029$ & Unit Root $p$-value $=0.033$ \\
\hline
\end{tabular}

Notes: See Table 1.

Table 16: Estimation of Threshold Autoregressive Model (WTI-Bonny)

$($ Lag Order $=2$; Delay Parameter $=2$; Threshold Estimate $=\$ \mathbf{\$ 0 . 9 3})$

\begin{tabular}{|l|l|l|l|}
\hline & $\begin{array}{l}\text { Column A } \\
\text { Regime 1 }\end{array}$ & $\begin{array}{l}\text { Column B } \\
\text { Regime 2 }\end{array}$ & $\begin{array}{l}\text { Column C } \\
\text { Wald Tests for Equality in } \\
\text { Individual Coefficients }\end{array}$ \\
\hline Intercept & -0.481 & 0.279 & 10.5 \\
$(0.230)$ & $(0.675)$ & Bootstrap $p$-value $=0.05$ \\
\hline $\mathrm{y}_{t-1}$ & -0.154 & -0.185 & 0.192 \\
& $(0.062)$ & $(0.035)$ & Bootstrap $p$-value $=0.763$ \\
\hline$\Delta \mathrm{y}_{t-1}$ & -0.139 & -0.171 & 0.067 \\
& $(0.108)$ & $(0.051)$ & Bootstrap $p$-value $=0.884$ \\
\hline$\Delta \mathrm{y}_{t-2}$ & -0.233 & -0.166 & 0.489 \\
& $(0.082)$ & $(0.048)$ & Bootstrap $p$-value $=0.641$ \\
\hline
\end{tabular}


Table 17: WTI-Brent Price Differential

\begin{tabular}{|l|l|l|}
\hline \multicolumn{3}{|c|}{ 1. UNIT Root Tests } \\
\hline ADF $(2)=-5.11$ & PP $(5)=-8.737$ & $A D F-G L S(4)=-4.400$ \\
\hline \multicolumn{3}{|c|}{ 2. Wald Tests for Threshold Effect ${ }^{2}$} \\
\hline \multicolumn{3}{|c|}{} \\
\hline sup-Wald Test $(1)=14.7$ & Stationary $p$-value $=0.121$ & Unit Root $p$-value $=0.134^{2}$
\end{tabular}

Notes: See Table 1. 
Table 18: WTI-Dubai Price Differential

\begin{tabular}{|c|c|c|}
\hline \multicolumn{3}{|c|}{ 1. UNIT Root Tests ${ }^{1}$} \\
\hline $\operatorname{ADF}(2)=-2.933$ & $P P(5)=-4.016$ & $A D F-G L S(2)=-2.872$ \\
\hline \multicolumn{3}{|c|}{ 2. Wald Tests for Threshold Effect ${ }^{2}$} \\
\hline sup-Wald Test $(2)=25.8$ & Stationary $p$-value $=0.004$ & Unit Root $p$-value $=0.007$ \\
\hline \multicolumn{3}{|c|}{ 3. Two-Sided Wald Test for Unit Root } \\
\hline Wald Stat $=13.8$ & Asym $p$-value $=0.040$ & Bootstrap $p$-value $=0.067$ \\
\hline
\end{tabular}

Notes: See Table 1.

Table 19: Estimation of Threshold Autoregressive Model (Dubai-Maya)

$($ Lag Order $=2 ;$ Delay Parameter $=2 ;$ Threshold Estimate $=\$ 4.99)$

\begin{tabular}{|l|l|l|l|}
\hline & $\begin{array}{l}\text { Column A } \\
\text { Regime 1 }\end{array}$ & $\begin{array}{l}\text { Column B } \\
\text { Regime 2 }\end{array}$ & $\begin{array}{l}\text { Column C } \\
\text { Wald Tests for Equality in } \\
\text { Individual Coefficients }\end{array}$ \\
\hline Intercept & 0.357 & 0.535 & 0.401 \\
& $(0.142)$ & $(0.243)$ & Bootstrap $p$-value $=0.858$ \\
\hline $\mathrm{y}_{t-1}$ & -0.130 & -0.089 & 0.465 \\
& $(0.050)$ & $(0.033)$ & Bootstrap $p$-value $=0.646$ \\
\hline$\Delta \mathrm{y}_{t-1}$ & -0.197 & -0.203 & 0.004 \\
& $(0.075)$ & $(0.063)$ & Bootstrap $p$-value $=0.960$ \\
\hline$\Delta \mathrm{y}_{t-2}$ & -0.332 & -0.027 & 12.1 \\
& $(0.063)$ & $(0.060)$ & Bootstrap $p$-value $=0.009$ \\
\hline$\Delta \mathrm{y}_{t-3}$ & -0.152 & 0.115 & 9.68 \\
& $(0.064)$ & $(0.056)$ & Bootstrap $p$-value $=0.02$ \\
\hline
\end{tabular}


Figure 1: Behaviour of Crude Oil Price Differentials

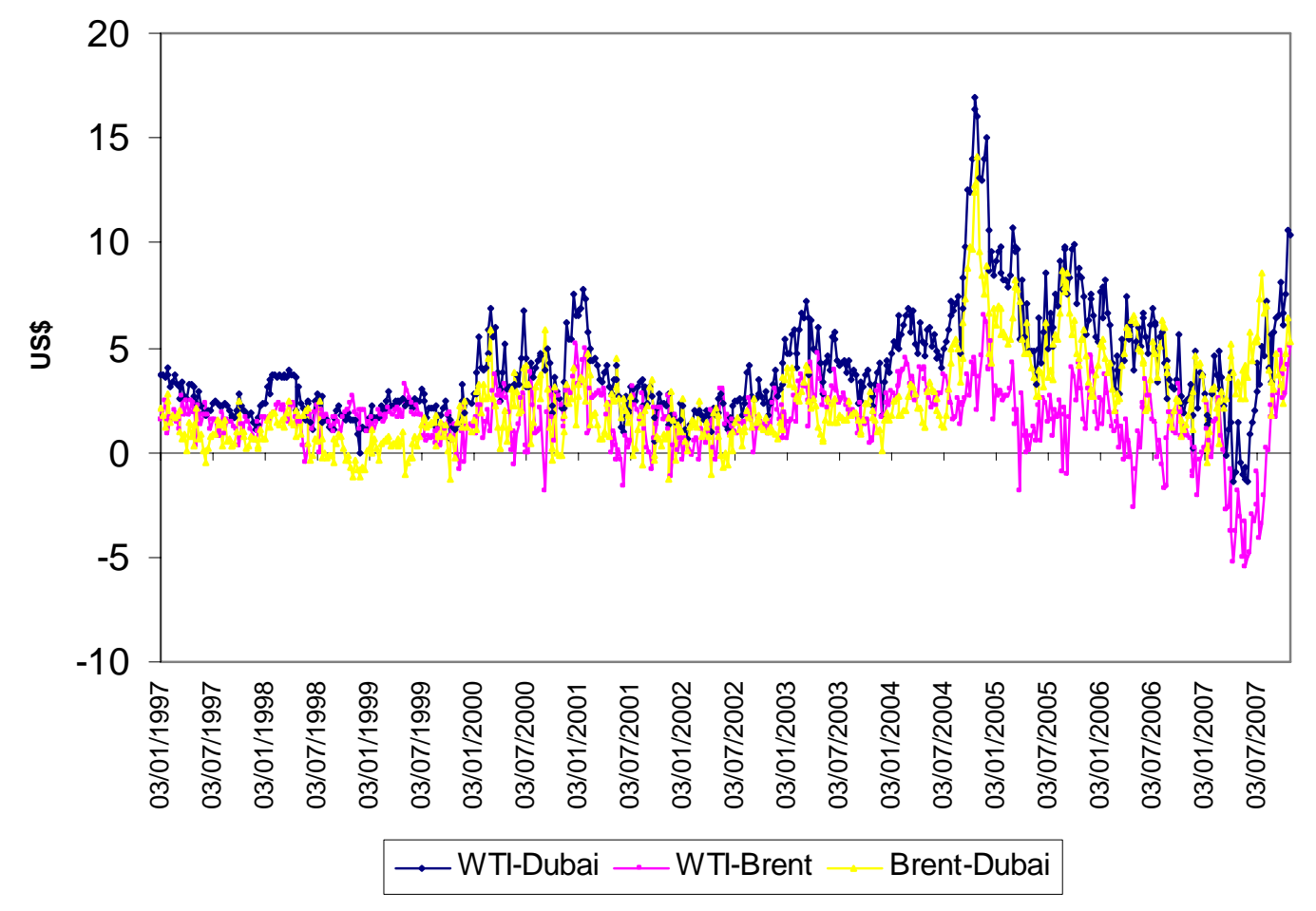


Figure 2: Identification of Threshold Regime for Sahara-Maya

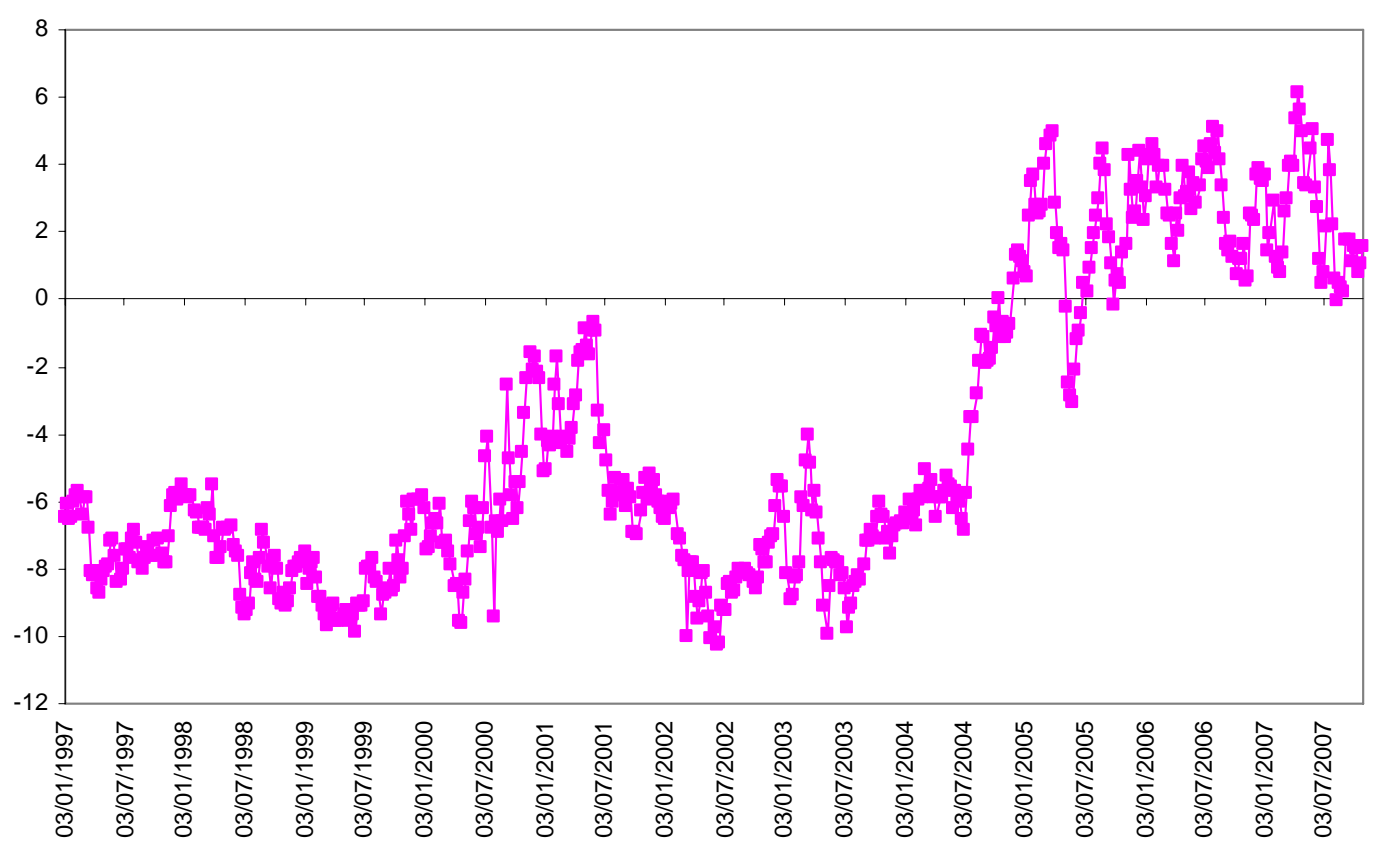


Figure 3: Identification of Threshold Regime for Sahara-Bonny

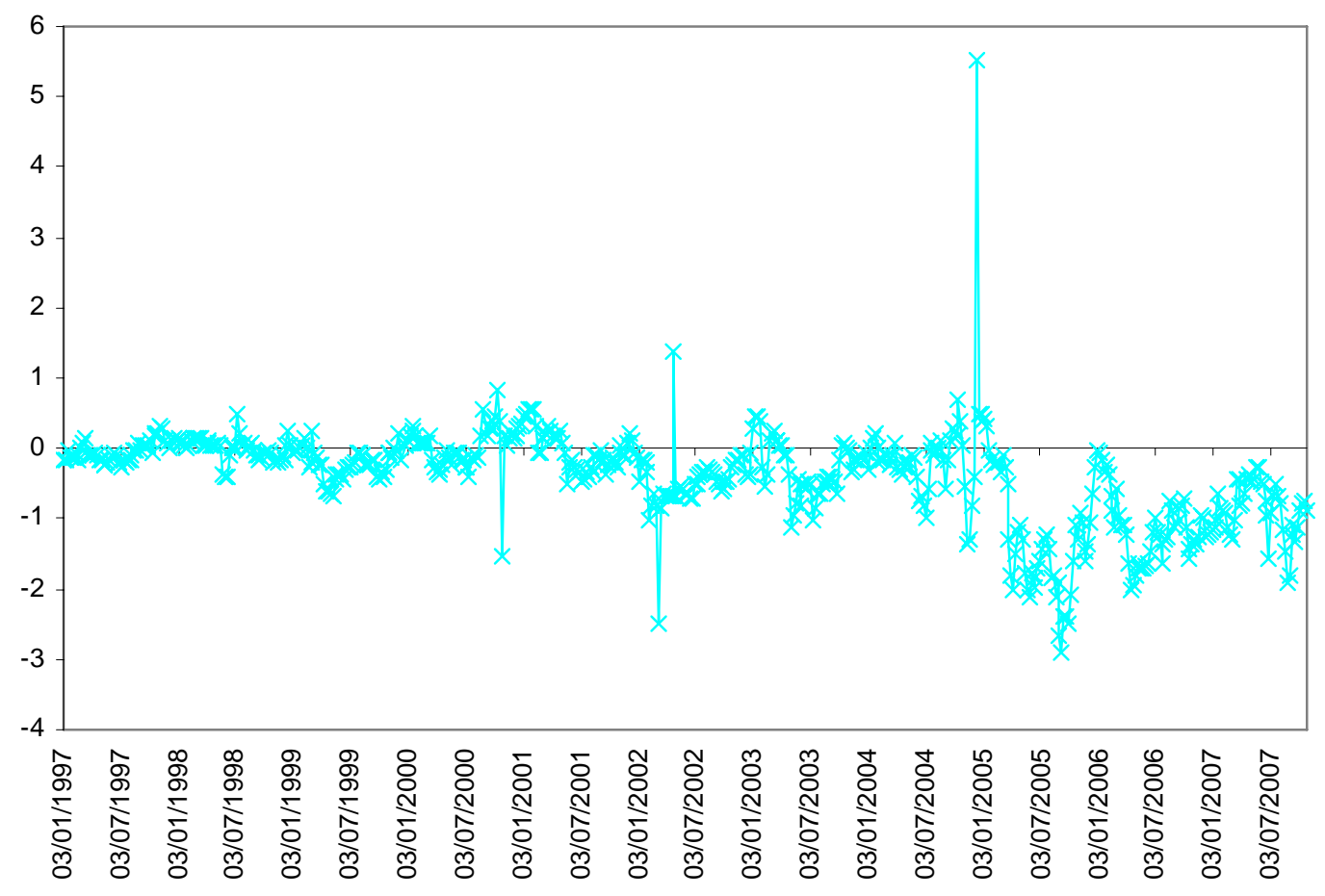

